\title{
Cirugía de catarata asistida con láser de femtosegundo en paciente con lente intraocular fáquico de Collamer
}

\section{Femtosecond laser-assisted cataract surgery in a patient with a Collamer lens}

\author{
Christian R. Fau ${ }^{1 *}$ y Romina G. Muñoz ${ }^{2}$ \\ ${ }^{1}$ Fundación Oftalmológica 2020, Iberoamerican Cochrane Network; ${ }^{2}$ Escuela de Tecnología Médica, Universidad Santo Tomás. Santiago, Chile
}

Paciente mujer de 47 años, con una alta miopía. Hace más de 10 años se realizó cirugía refractiva mediante lente fáquico intraocular de Collamer en ambos ojos. En el momento de su evaluación presentaba en el ojo derecho catarata cortical anterior, secundaria al contacto del lente fáquico con la cara anterior del cristalino (C5NOP0), lo que comprometía el eje visual y solo permitía una visión de 0.3 con corrección de lentes y excéntrica'; su ojo izquierdo tenía visión de 0.05 , producto de retinopatía miópica con daño foveal.

La paciente, después de consultar diferentes médicos, optó por realizarse una cirugía de catarata asistida con láser de femtosegundo (equipo VICTUS Technolas). Dado el alto riesgo de presentar una adherencia entre el lente fáquico y la cápsula anterior del cristalino, se realizó la capsulorrexis a través del lente fáquico², luego se procedió a completar la cirugía realizando: las paracentesis con un cuchillete; la extracción del lente fáquico; el retiro de la capsulorrexis, que resultó continua sin zonas de adherencias; la facoemulsificación y colocación de lente intraocular, y se terminó la cirugía sin incidentes.

El realizar la capsulorrexis con el láser a través del lente fáquico genera la incertidumbre de si los resultados serán los esperados ${ }^{3}$ y si la capsulorrexis será continua, dado el riesgo de pérdida de potencia o pérdida de precisión del láser, producto de tener que

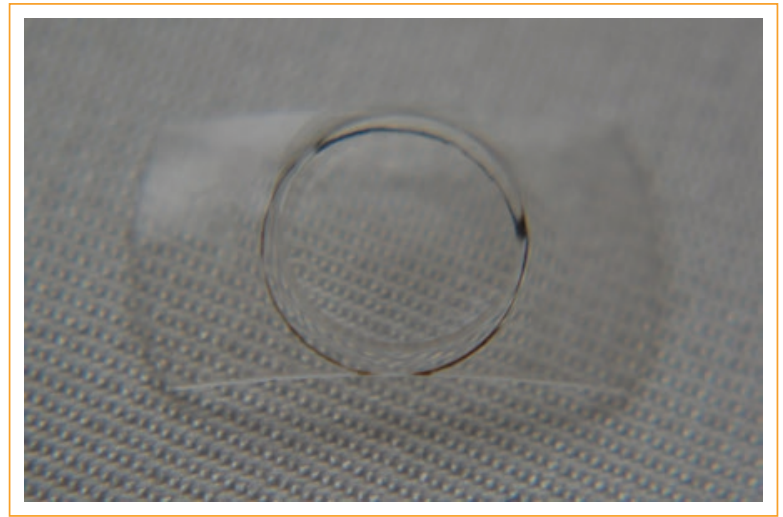

Figura 1. Cara anterior del lente intraocular fáquico, se trasluce línea negra de corte generada por el láser de femtosegundo en la cara posterior del lente.

traspasar un material para el cual no fue diseñado. Tanto en este caso como en el artículo de Li, et al. ${ }^{3}$ no se encontró que el lente fáquico implantado interfiera con la transmisión de la energía del láser de femtosegundo. En este caso, el poder generado por el láser no solo generó un corte continuo de la capsulorrexis sin inconvenientes, sino que también marcó el lente fáquico por su cara interna, lo cual se aprecia en las fotos (Figs. 1 y 2). Esto demuestra que el láser de femtosegundo no solo puede realizar una capsulorrexis continua a través de 


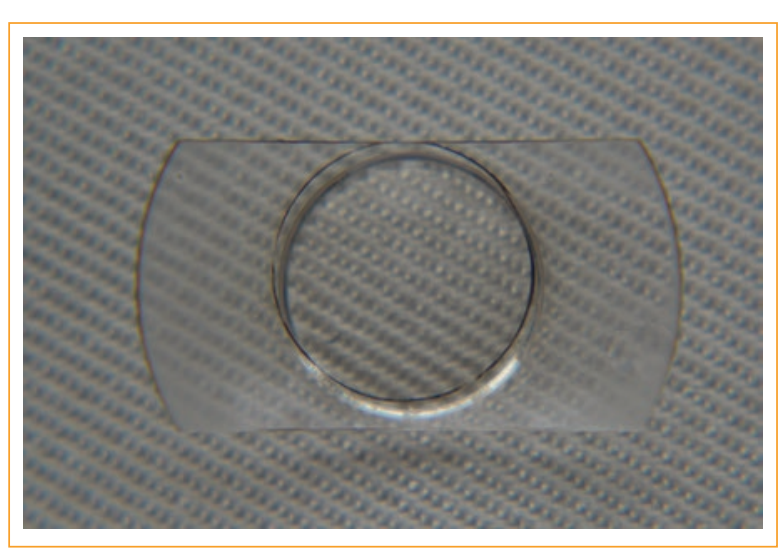

Figura 2. Cara posterior de lente intraocular fáquico, con línea negra de corte, generada por el láser de femtosegundo.

un lente fáquico sin complicaciones, sino que también genera un intervalo de corte, tanto hacia delante como hacia atrás del punto previamente programado a ser cortado, no parece por la marca en el lente que esta zona se prolongue hacia los lados. Esto es de especial importancia al realizar el corte del núcleo, ya que este intervalo de corte puede romper la cápsula posterior si la fragmentación del núcleo se acerca mucho.

En conclusión, la utilización de este método es seguro y efectivo ${ }^{2,3}$, lo que da a los cirujanos una opción adicional de tratamiento en estos pacientes, con altas expectativas de función visual y muchas veces con recuentos de células endoteliales reducidos.
Finalmente, el resultado del paciente a los 6 meses de la cirugía fue de 0,8 parcial con corrección y sin complicaciones.

\section{Conflicto de intereses}

Los autores no declaran ningún conflicto de intereses.

\section{Responsabilidades éticas}

Protección de personas y animales. Los autores declaran que los procedimientos seguidos se conformaron a las normas éticas del comité de experimentación humana responsable y de acuerdo con la Asociación Médica Mundial y la Declaración de Helsinki.

Confidencialidad de los datos. Los autores declaran que han seguido los protocolos de su centro de trabajo sobre la publicación de datos de pacientes.

\section{Derecho a la privacidad y consentimiento informa-}

do. Los autores han obtenido el consentimiento informado de los pacientes y/o sujetos referidos en el artículo. Este documento obra en poder del autor de correspondencia.

\section{Bibliografía}

1. Packer M. Meta-analysis and review: Effectiveness, safety, and central port design of the intraocular collamer lens. Clin Ophthalmol. 2016;10:1059-77.

2. Schultz T, Schwarzenbacher L, Burkhard Dick H. Comparing femtosecond laser-assisted cataract surgery before and after phakic intraocular lens removal. J Refractive Surg. 2018;34(5):343-6.

3. Li S, Chen X, Kang Y, Han N. Femtosecond laser-assisted cataract surgery in a cataractous eye with Implantable Collamer Lens in situ. $\mathrm{J}$ Refractive Surg. 2016;32(4):270-2. 